\title{
ASPECTOS CULTURALES DE LA TRADUCCIÓN DEL HUMOR SOBRE LA MUJER
}

\author{
MOHAMED EL-MADKOURI MAATAOUI \\ Universidad Autónoma de Madrid
}

Recibido: $15 / 09 / 2014$

Aceptado: 24/11/2014

\section{Resumen}

El discurso lúdico está impregnado de referencias extralingüísticas de índole social y cultural, amén de los ya consabidos procedimientos metalingüísticos y de autorreferencia, de ahí que una traducción o interpretación del mismo que mantenga la misma carga humorística resulte complicada. Esto se debe no solamente a las distintas complejidades lingüísticas implicadas en su construcción, sino también a las atribuciones culturales que se le confieren. No estamos hablando, por tanto, de la traducibilidad lingüística, sino de la cultural. Es decir, ¿son aceptables del mismo modo los chistes sobre la mujer a ambas orillas del Mediterráneo? Partiendo de este planteamiento, el presente trabajo tiene por objeto analizar lo universal y lo particular en el trasvase del chiste sobre la mujer de una cultura a otra. Para ello, se han elegido un par de culturas aparentemente diferentes como son la árabe y la española, aunque metafóricamente se designe a ambas con el nombre de cultura mediterránea. Así, se intentará averiguar cómo se representa a la mujer en el chiste desde los siguientes parámetros: el físico, el intelectual y el moral.

Palabras clave: chiste, mujer, traducción, traductología, interculturalidad

\begin{abstract}
The playful discourse is imbued with references extralinguistic social and cultural factors, in addition to the already well known procedures and metalinguistic self-reference, hence its translation and interpretation with the same humorous load resulting complicated. Not only by the different linguistic complexities involved in its construction, but by the cultural powers conferred. Departing from this approach, this paper aims to examine the universal and the particular in the transfer of the joke about the
\end{abstract}


woman from one culture to another. For this we have selected a pair of seemingly different as Arabic and Spanish cultures, though they are both metaphorically designate the name of Mediterranean culture. Thus, try to figure out how the woman depicted in the joke from the following parameters: physical, intellectual and moral.

Keywords: Joke, Woman, translation, Translation Studies, intercultural 


\section{Introducción}

En culturas distintas no siempre se ríe de lo mismo ni de la misma manera. Los aspectos cromáticos del discurso chistoso no son simétricos entre una lengua y otra, ni entre una cultura y otra. Además, no todas las lenguas tienen colores para los chistes, y en las que los tienen, no se corresponden obligatoriamente con los de la lengua de partida. Tampoco existe necesariamente una simetría de significación (que no de significado) entre el léxico de lenguas distintas. En el marco del discurso humorístico, se ha optado por el chiste y el lenguaje humorístico en general por varias consideraciones:

1. El discurso humorístico es anónimo. No viene suscrito por ningún autor ni aparece patentado por ninguna institución.

2. Al ser despersonalizado, su autoría es asumida por toda la sociedad y cultura en que se produce y se recibe. En este sentido, podemos hablar de una autoría colectiva, que incluye a los que los escuchan y se ríen con ellos.

3. Al ser un constructo discursivo colectivo, su análisis nos permite rastrear estereotipos culturales.

4. Al estar impregnado de referencias extralingüísticas de índole social y cultural, amén de los ya consabidos procedimientos metalingüísticos y de autorreferencia, resulta complicado llevar a cabo una traducción o interpretación que mantenga la misma carga humorística. Esto se debe no solamente a las distintas complejidades lingüísticas implicadas en su construcción, sino también a las atribuciones culturales que se le confieren.

Desde este planteamiento, consideramos pertinente el estudio de la presencia y caracterización de la mujer en el chiste, entendido siempre como constructo discursivo abstracto. Cabe señalar al respecto que para la elaboración de este estudio se han tomado como ejemplo chistes en la Red. En el caso árabe, las nuevas tecnologías representan el discurso real social, un cambio generacional y conceptual. Igualmente, en el caso español se accede a chistes de todo tipo en la Red, traspasando la barrera de lo «políticamente correcto». 
En todos los casos, la caracterización discursiva de la mujer es controvertida. La mujer, en los distintos discursos, en general (novela, teatro, cine, poesía), siempre ha simbolizado a la vez la ternura y la insensibilidad, el amor y el desprecio, la ingenuidad y la astucia, la nobleza y la perfidia, la lealtad y la traición, la compasión y la crueldad. Sin embargo, en el chiste, como demostraremos en este artículo, está más presente lo negativo que lo positivo.

\section{La presencia femenina en el chiste}

Tanto en árabe como en español la presencia femenina en el chiste es notoria. El cuerpo femenino aparece reiteradamente en el chiste bajo distintas manifestaciones: como objeto de deseo, de codicia, de protección, de posesión, pero también como cuerpo desechado, repudiado, aborrecido... En esta representación, el discurso chistoso está polarizado entre el cuerpo extremadamente «bello» y el cuerpo extremadamente «feo». En ello participa reseñablemente la dimensión temporal, encontramos a la jovencita «tentadora» en oposición a la «vieja» desechada, pero que se resiste a tirar la toalla. Esta dicotomía, no obstante, no siempre es paralela a la edad real y física de la mujer, sino que encontramos la vieja y la recién conocida, la primera y la segunda. Junto con este vector temporal interviene también, en la construcción del chiste, la dimensión intelectual: la mujer es generalmente ingenua y con las facultades mentales reducidas, y cuando el chiste hace una representación contraria, la capacidad intelectual se convierte en astucia y perfidia. En cuanto a los valores morales de la mujer, quedan supeditados a sus circunstancias personales y emocionales, por lo que aparecen inconstantes. Es decir, que la mujer se presenta, por lo general, más en el chiste español que en el árabe, moralmente insolvente; de hecho, se insiste más en la infidelidad femenina en el chiste español que en el chiste árabe.

\subsection{El cuerpo femenino en el chiste}

Antes de hablar del cuerpo femenino, tema del chiste tanto en árabe como en español, cabe preguntarse qué tipo de mujer aparece en este tipo de discurso.

La mujer más representada en el discurso lúdico no es ni la madre, ni la hermana, ni la hija, sino una mujer ajena, anónima primero y esposa después, más en el chiste español que en el árabe. Es decir, la mujer más representada es la mujer-cuerpo sujeta a la posesión y al disfrute. Es la mujer como objeto. Cabe matizar, sin embargo, que, aunque la madre, la hermana y la hija están menos presentes, esto no significa que sean inexistentes, especialmente en español. De hecho, existen en la cultura española chistes sobre la hija, la 
madre y la hermana muchísimo más presentes y relevantes que en los distintos países árabes. En el mundo árabe la mujer-cuerpo que aparece en el chiste es la mujer ajena a toda relación consanguínea. Este hecho plantea una importante cuestión traductológica, ya que, salvando los demás problemas de la traducción del chiste, los árabes son traducibles al español, pero no así tanto los españoles al árabe, por las siguientes razones:

1. El chiste sobre la mujer parece de autoría masculina. Todo indica que es el hombre quien inventa estos chistes, para reírse con otro $u$ otros hombres, armando estos constructos lúdicos con cuerpos femeninos. Una encuesta informal reveló que siete mujeres de entre 27 y 40 años de edad, árabes y españolas encuestadas, creen que la autoría de estos chistes corresponde a los hombres. Por ello, lo que haría gracia a unos, no la haría necesariamente a otros, especialmente en el mundo árabe.

2. Cuando se habla de la mujer-cuerpo, en realidad se habla de la mujer como objeto sexual. Cuerpo y sexo están muy estrechamente relacionados en el chiste sobre la mujer. Sin embargo, un árabe no puede imaginarse que su hermana, madre o hija puedan ser objetos sexuales ni propios ni ajenos, aspecto irrelevante en español. Por ello, el chiste español traducido al árabe deja de ser chiste para convertirse en una broma de mal gusto.

3. La mujer-cuerpo en árabe es una mujer libre de todo compromiso matrimonial o consanguíneo. Es una mujer que no es familiar y generalmente es soltera. En otras palabras, es un cuerpo sexual anónimo. Hay pocas connotaciones sexuales sobre mujeres familiares o casadas.

4. Muy en relación con lo anterior, la mujer del chiste es más infiel en español que en árabe. Es decir, desde el punto de vista cuantitativo, la mujer infiel aparece más en el chiste español que en el chiste árabe, a pesar de que libros como Las mil y una noches están plagados de mujeres infieles. Sería interesante investigar por qué hay más presencia de mujeres infieles en la literatura árabe formal que en la popular.

\subsection{La relevancia de la mujer-cuerpo-sexo en el chiste}

El sexo es muy relevante en el chiste español sobre la mujer, además es un sexo explícito, claro y hasta pornográfico. En el caso del chiste árabe, esta presencia es más bien sutil o simbólica, y necesita de una serie de abstracciones y de operaciones interpretativas para poder ser entendido. Es más, este tipo de chistes árabes se puede contar en presencia de niños pequeños sin que estos los entiendan. De hecho, los chistes árabes no mencionan, generalmente, de 
forma explícita ningún órgano sexual, ni femenino, ni masculino. Además, el discurso sobre el sexo en español está extendido, mientras que en árabe está circunscrito a tiempos y espacios bien determinados. Es decir, en español se habla generalmente de sexo con todo el mundo, a cualquier hora y en cualquier sitio. En el caso del mundo árabe, el discurso sobre mujer-sexo aparece limitado por el tipo de interlocutor y las dimensiones espacio-temporales. Las tres variables condicionantes de la circulación del chiste árabe sobre la mujercuerpo-sexo son:

1. El receptor del chiste sexual: cuando el discurso sobre sexo es explícito en árabe su exteriorización se ve determinada por el tipo de destinatario a quien va dirigido. El cuentachistes no puede decidir por sí solo cuándo los cuenta, independientemente de a quién vayan dirigidos y del tipo de audiencia. Esto parece universal y se da igualmente en español, sin embargo, en el caso de la cultura árabe genuina, este tipo de chistes se cuenta entre iguales. Es decir, no se pueden contar cuando hay diferencias de edad. El desfase generacional limita la exteriorización del discurso sobre sexo. Uno no puede contar un chiste explícitamente sexual a otros en presencia de sus hijos o padres, por ejemplo. Del mismo modo, no es común contar un chiste sobre el cuerpo de la mujer y de connotaciones sexuales explícitas en presencia de oyentes que pudieran ser hijos o padres de quien los cuenta.

Otra variable que también debe tenerse en cuenta es el sexo del oyente. Cuando el sexo del hablante es distinto del sexo del oyente (a no ser que exista demasiada familiaridad y no parentesco consanguíneo entre ellos), el chiste sexual es mal recibido. Estamos hablando aquí de lo común y genuino, ya que muchos colectivos jóvenes, especialmente en países como Marruecos, Túnez y el Líbano están occidentalizados, por lo que se rigen por otros patrones culturales. De hecho, esta occidentalización se percibe como algo extremadamente negativo en algunos de sus aspectos. No en vano, muchos analistas de estos países atribuyen la cultura del cuerpo, la droga o la violencia juvenil en el sistema educativo a la globalización y a la occidentalización:

El mundo está experimentando grandes cambios en diferentes campos. Esto ha tenido un impacto negativo significativo en el sistema de valores y principios humanos y morales. Este comportamiento ha dado lugar a una variedad de fenómenos negativos como la violencia, el consumo de drogas... ${ }^{1}$ [Traducción propia]

1. <http://www.hibapress.com/fr/details-3138.html> consultado el 03-05-2014. 
Esta reflexión académica es corroborada con un lenguaje más directo por un responsable policial en el mismo acto discursivo:

Las escuelas son un tipo único de sociedad donde florecen muchos comportamientos irreflexivos relativos a la violencia, la agresión, la droga, la delincuencia, los asaltos, las lesiones... entre los propios alumnos y entre los alumnos y el cuerpo docente ${ }^{2}$. [Traducción propia]

Aunque estas citas no hablan explícitamente de Occidente, plantean el problema de la alteración del sistema de valores y de los principios humanos y morales. Esto se debe a que el mundo está interconectado, como si viviéramos en una pequeña aldea global. De hecho, quien pronuncia las palabras de la primera cita es un responsable académico de la región de Tadla-Azilal, en los confines de la cordillera del Atlas Medio marroquí, en el marco de un acuerdo ente las autoridades educativas y las policiales de la región para prevenir la delincuencia estudiantil, tradicionalmente insignificante en esa zona. No es de extrañar que este cambio moral afecte también a la cultura juvenil en general y a su percepción del otro sexo, en particular. En efecto, el cuerpo femenino se ha cosificado demasiado en el leguaje de este «tipo único de sociedad», especialmente en el de los países mencionados anteriormente, tema que trataremos en un futuro trabajo.

2. El espacio físico donde se desarrolla el discurso chistoso no es menos importante que el tipo de interlocutor (edad y sexo). En árabe existe el fraseologismo «a cada lugar, su discurso». Expresado de otro modo, el contexto comunicativo predetermina lo que se puede decir y cómo debe decirse. Un chiste sobre el cuerpo femenino o masculino con connotaciones sexuales no se puede contar, por ejemplo, en el hogar familiar o en un contexto discursivo en el que hay personas poco conocidas y con la cuales no existe una estrecha amistad o cordialidad. Tampoco se cuenta en voz alta, audible para los comensales de la mesa de al lado, por ejemplo. Este tipo de chistes suele contarse como si de una verdadera confidencia se tratase.

3. El momento también determina a quién y cuándo se puede contar un chiste sexual que corporeiza a la mujer. Si en el penúltimo párrafo hemos visto que la edad del oyente es determinante, también lo es el momento y la motivación con que se cuenta. El chiste sobre sexo en el mundo árabe es más nocturno que diurno, y es más frecuente en el tiempo libre (extraescolar y fuera del ambiente serio del trabajo). Sin embargo, esta es una tendencia general, cuantitativamente relevante, pero que no excluye que existan personas, hombres

2. Ibídem.

Feminismo/s 24, diciembre 2014, pp. 245-264 
generalmente, que los cuenten «fuera de tiempo» y con fines más bien provocativos, cuando parte del auditorio es femenino. Aquí ya no se cuenta el chiste para «hacer reír», sino para provocar a la mujer, especialmente cuando las relaciones entre estas personas dejan que desear. Es decir, la finalidad explícita en este caso ya no es lúdica, sino ofensiva.

Estas tres variables son, por tanto, determinantes de las circunstancias de la producción de chistes sobre la mujer con connotaciones sexuales, y son determinantes, aunque en menor grado, de la construcción de los mismos. Por ello, el problema de la traducción en estos casos no es inherente al propio discurso chistoso, sino a su divulgación y a las limitaciones culturales de su uso. Es decir, no existe simetría entre los auditorios. Si nos imaginamos, por ejemplo, una representación teatral impregnada de estos chistes que hubiera que traducir y escenificar en el mundo árabe, el teatro no tendría seguramente ni la afluencia ni el mismo tipo de espectadores que en España. Estos chistes, considerados «obscenos» y degradantes, no tendrían la misma aceptación que en la cultura origen.

En árabe, sin embargo, existen chistes sobre amoríos (no sexuales) adolescentes en las redes sociales en los cuales las adolescentes y preadolescentes son objeto de mofa, como el siguiente:

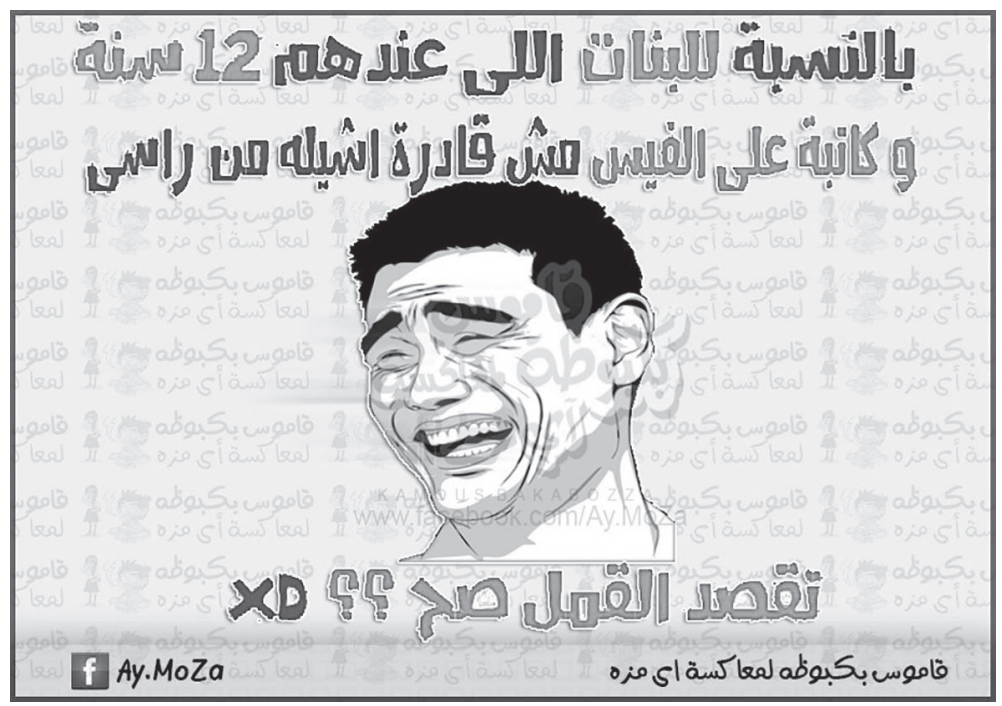

Imagen 1 
Una posible traducción de la imagen 1 podría ser la siguiente: «Las chicas de doce años que escriben en el Facebook que " No se los pueden quitar de la cabeza!"... ¿A qué se refieren? A los piojos, ¿verdad? (-)». Este tipo de chiste árabe es abundante en la Red: el objeto de la risa es siempre un niño o una niña que quiere ser mayor o pretende hacer cosas de mayores. Es decir, en el caso de las preadolescentes de «los piojos en la cabeza», el chiste es sutil y hasta educativo. En este caso, se pone de relieve la disfunción mencionada más arriba. Se supone que los doce años son una edad en la que no se debe tener nada en la cabeza que no sea, en el peor de los casos, piojos.

\subsection{El cuerpo femenino, mujer casada}

La oposición mujer-casada y mujer-independiente es más relevante en árabe que en español. La mujer en español es un cuerpo de deseo o de burla sexual con independencia de si está casada o no. En árabe se hace una diferencia entre mujer casada y mujer no casada. Los chistes sexuales sobre mujeres árabes como objeto de deseo ajeno evitan a las casadas. En español, sin embargo, el estado civil de casada de la mujer-objeto parece irrelevante para el chiste sexual. Es frecuente ver en la calle a hombres piropear a mujeres, con independencia de si están casadas o no. En el mundo árabe, en cambio, son poco frecuentes los chistes sobre mujeres casadas como objetos sexuales, es decir, como objeto de deseo o de repulsa por parte del sujeto de la enunciación. Los chistes sexuales árabes existentes sobre casadas son, al contrario, para reírse de sus disfunciones con sus maridos o de estos entre ellas. Así, desde siempre el chiste árabe de contenido sexual mayoritario ha sido sobre la mujer casada.

No obstante, existe una coincidencia entre España y muchos países árabes cuando el chiste incurre en el propio matrimonio y casamiento, más que en el cuerpo femenino. Cuando se focaliza en el matrimonio, se difumina la caracterización corporal positiva de la mujer casada y aparecen otras consideraciones relativas a la vida conyugal. En este aspecto concreto, los chistes son traducibles entre el árabe y el español. Además, tanto en árabe como en español hay abundantes chistes relativos a la mujer en la vida matrimonial. En realidad, estos chistes no focalizan en la mujer, sino en la institución matrimonial. Parece ser que la mujer es objeto de deseo hasta que se casa. Por ello, ambas culturas coinciden en los siguientes aspectos: el descuido de la casada de sí misma, su excesivo gasto, su autoritarismo, su opresión al esposo y, finalmente, su disfunción sexual (explícita en español e implícita en árabe). En este caso, podría afirmarse, a excepción del último punto, que la traducibilidad cultural de estos chistes es posible entre el árabe y el español. 


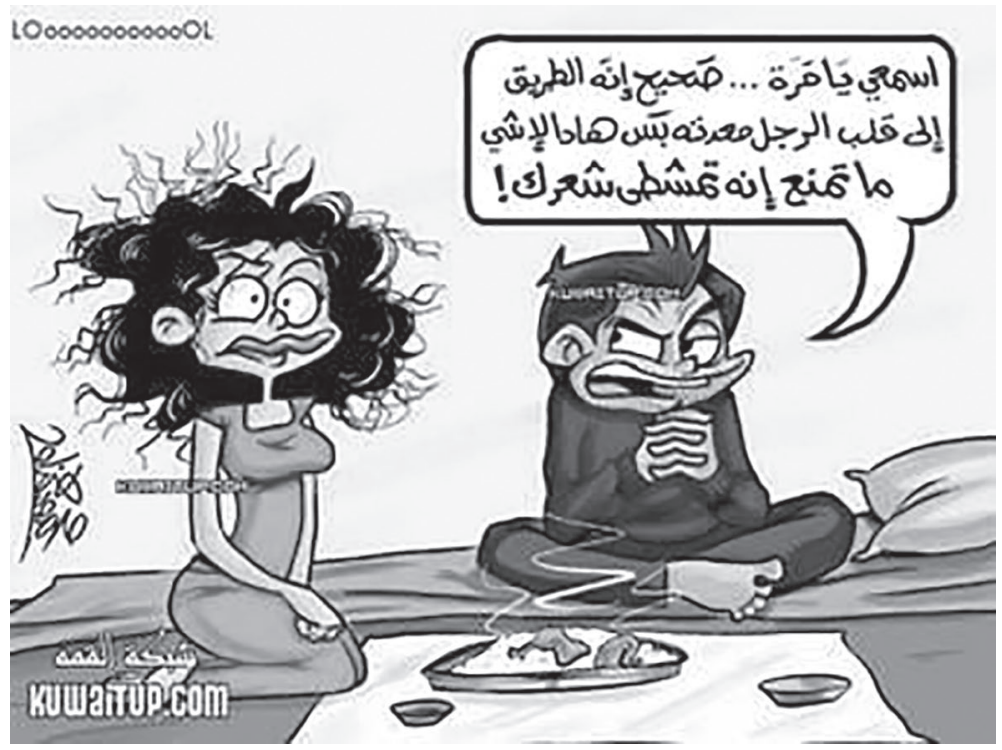

Imagen 2

Aquí se presenta la imagen de una mujer árabe descuidada. Este chiste reza:

Escucha, mujer, es verdad que a un hombre se le conquista por el estómago, pero esto no impide que te peines un poco.

La gordura está igualmente relacionada con el cuerpo de la mujer. En este sentido, el símil de la vaca es común para representar a la mujer, tanto en árabe como en español. Sin embargo, el término foca es privativo del chiste español, aunque aparece sustituido en árabe por elefanta, que no se presenta en español. De todos modos, la comparación con el animal es muy recurrente en los chistes en ambas lenguas. Sin embargo, las connotaciones propias de cada uno son distintas, aunque en este trabajo hemos hecho hincapié solo en los que califican a la mujer casada. Sirva de ejemplo este chiste árabe:

Esto es un hombre que habla con su mujer y le dice: «La vida se ha convertido en un zoo. Fíjate en mí: me levanto como un caballo, voy a trabajar como un burro, vuelvo jadeado como un perro y me acuesto ${ }^{3}$ con una vaca».

3. El verbo real en árabe es «dormir» [me duermo con], creándose una ambigüedad muy propia de la construcción de los chistes árabes, como se ha dicho anteriormente, sobre el verdadero sentido de este verbo. Haciendo uso de la característica de la explicitud propia 
Parece ser que la estética de la mujer delegada no es un lastre solo para las occidentales, sino también para la mayoría de las mujeres de los países árabes. La siguiente viñeta reproduce el mismo tópico:

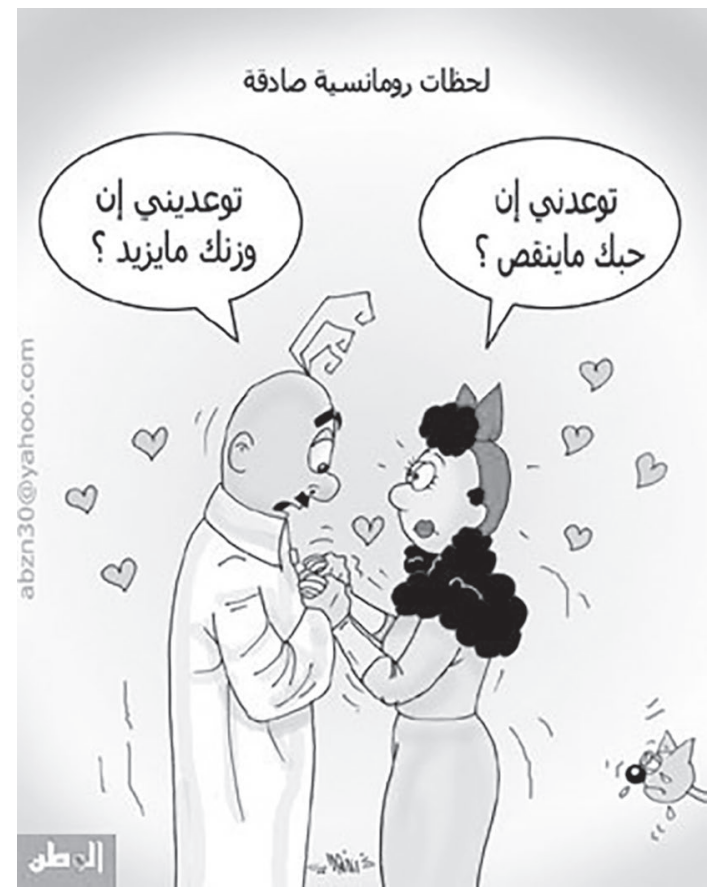

Imagen 3

El texto de esta imagen dice:

Momentos románticos de sinceridad

Ella a él: «¿Me prometes que nunca disminuirá tu amor por mí?»

Él a ella: «¿Me prometes que nunca subirás de peso?»

Tanto en español como en árabe, el tópico parece ser que la mujer es guapa, valorada y apreciada hasta que se casa. Entonces van desmejorando su amor por el marido, su estética personal y sobre todo sus relaciones maritales, como en este chiste español:

de los chistes españoles, se ha traducido por «acostarse», que es como lo entiende también un adulto árabe. 
¿Cuál es la diferencia entre una novia, una amante y una esposa?

Que la novia te dice «jay, qué dulce!», la amante dice «jay, qué vigor!», y la esposa dice «hay que pagar la luz, hay que pagar el teléfono, hay que pagar el gas...».

Esta caracterización cultural de la mujer en el matrimonio hace posible la aceptabilidad y, por tanto, la traducibilidad de los chistes y anécdotas sobre estos temas. Sin embargo, cabe señalar una excepción. Algunos chistes españoles son demasiado explícitos sobre el tema sexual -como ya se ha comentado-, mientras que sus homólogos árabes son más bien implícitos. Por ello, serían más aceptables los chistes árabes en español (aunque resultasen light), que los españoles en árabe, que perderían su gracia por pecar, a veces, de «vulgares». Los chistes árabes sobre este tema no son tan descriptivos y anatómicos como los españoles. La simbología, y consecuentemente la inferencia, parecen ser un requisito esencial en el chiste árabe sobre el sexo no solo en el matrimonio, sino en general.

Ahora bien, la disfunción sexual varonil es un tópico que se da en chistes de ambas lenguas, aunque está más naturalizada en árabe que en español. En la cultura española, parece ser que la imagen del macho queda salvaguardada, como en el siguiente ejemplo:

-Mi marido es tocólogo.

-Pues el mío es meteorólogo.

- iQué suerte tienen algunas!

Está claro que la construcción léxica de este chiste no podía ser de otro modo, pero el vigor del macho ibérico es poco cuestionado, por lo menos no del mismo modo en que aparece cuestionada la actividad sexual femenina de la española. No se ha podido encontrar ninguno parecido en árabe, en el que la mujer como sujeto del chiste no cuestione la virilidad del hombre. Ahora bien, desde el punto de vista traductológico, este tipo de chistes es traducible al árabe, aunque en esta cultura existen chistes que parecen hechos al revés, es decir, sobre mujeres que cuestionan a los hombres:

Esto es uno a quien no le gusta cómo cocina su mujer. Coge y escribe un letrero que le cuelga en la cocina: «A Dios le gusta que, cuando uno de vosotros haga algo, lo haga perfecto». La mujer coge el letrero y se lo cuelga en el dormitorio (:).

Aquí el hombre árabe no es tocólogo ni meteorólogo, sino que parece incumplir lo que pregona. La perfección no solo debe demostrarla la mujer, en este caso, cocinando, sino también el hombre en otros menesteres. Cabe mencionar que, como en casos anteriores, se precisa explicitar un dato cultural que puede pasar desapercibido a una persona con pocos conocimientos de 
la cultura islámica. La frase entrecomillada que aboga por la perfección en lo que se haga es un dicho de Mahoma, profeta del islam, que exhorta a sus seguidores a la perfección. El hombre del chiste lo aplica a su conveniencia en un sentido, y la mujer se lo devuelve, en otro.

En el mundo árabe, la mayoría de los chistes de contenido sexual versa sobre la mujer, pero esta se presenta como un ente anónimo. La casada no se presenta generalmente como diana directa del chiste sexual.

No obstante, se ha observado un cambio significativo en la profusión de los chistes sexuales que algunos atribuyen, como se ha visto anteriormente, a la cultura occidental. Con todo, cabe destacar que el chiste genuinamente árabe era el que remarcaba la torpeza del hombre en temas sexuales y en el conocimiento del cuerpo femenino, con lo que el chiste clásico participaba en cierta medida en la educación sexual de las nuevas generaciones, cuando ya son maduras para ello. Sin embargo, en la actualidad, se ha observado la irrupción de nuevos contenidos sexuales en los chistes árabes sobre la mujer. Esto es debido a varios factores:

1. El progreso de las nuevas tecnologías. Las pantallas de los ordenadores dan la impresión de cierto anonimato y previenen de la posible reacción negativa inmediata ante un auditorio real. De hecho, se codifican de forma escrita cada vez con más frecuencia, cuando su esencia es tradicionalmente una codificación oral.

2. Como consecuencia de lo anterior y por la liberación del espacio audiovisual en prácticamente todo el mundo, se asiste a un cambio sustancial en las culturas árabes, que aparecen cada vez más occidentalizadas, aunque esto no afecta a todas las generaciones ni a ambos sexos por igual.

3. La tercera causa es debida, en los mismos términos anteriores, a la globalización y al asentamiento de una gran diáspora de árabes en países occidentales con culturas que, a ojos de la cultura árabe clásica, «banalizan» el sexo. De hecho, cuando se «pesca» un chiste en la Red, como se ha hecho para la presente investigación, se sabe que es árabe porque aparece escrito en una de la variantes de la lengua árabe, por lo que se puede saber que es libanés, sirio, iraquí, marroquí, etc.; pero no se puede determinar a ciencia cierta si su autoría es interna o externa, o sea, si ha sido creado dentro del mundo árabe o por árabes asentados en países occidentales. 
Este cambio en la cultura lúdica sobre el chiste y el cuerpo, tanto el femenino como el masculino, ha sido objeto de varios artículos publicados en el mundo árabe. Sirva de ejemplo este fragmento:

«Habla para que te vea» es uno de los eslóganes más certeros para manifestar que la manera de hablar de una persona revela su cultura y educación, incluso da cuenta de su estado psicológico. El mundo de los jóvenes, el mundo de la adolescencia, distinto, convulso y siempre agitado, se entiende por medio de sus manifestaciones lingüísticas, sus expresiones, sueños y aspiraciones. El chiste como una de las fuentes de conocimiento que practicamos diariamente cumple una función paralela a las otras fuentes de cultura y demás información, y puede incluso que las supere [...].

Los chistes desempeñan un papel fundamental en la cultura sexual, pero esta vez de forma errónea, algo indudablemente muy negativo [...], una «brasa de fuego» que acabaría destruyendo su futuro y sus mentes. ¿El cabeza de familia que se yergue como guardián para que su hijo no vea una película pornográfica o adquiera una revista «sexual» podría acaso ponerle un candado en la boca o en la de sus amigos para impedirle contar chistes malsonantes? ${ }^{4}$

Este ejemplo refleja una verdadera preocupación por la trivialización y banalización del sexo por parte los jóvenes árabes, por encima de las categorías genuinas de esta cultura que rechazan el sexo fuera de una unión de pareja estable. El autor de la cita, después de excusarse por no poder reproducir una muestra de estos chistes criticados, facilita, sin embargo, el siguiente ejemplo:

Una caricatura publicada recientemente por una revista muestra a un joven que quiere pedir la mano de una chica a su padre. Como es de costumbre, existe una dote preceptiva, que se acuerda antes del matrimonio. El joven dice en la caricatura:

-Puedo entregar la mitad de la dote y llevármela solo los jueves y viernes.

Antes de comentar esta cita, cabe proporcionar las claves culturales de su interpretación. Primero, la dote la constituyen los regalos, el oro, las joyas y todo lo que el novio ofrece a la novia, y que se acuerda generalmente entre las familias de los novios. Varía entre los distintos países árabes y va de lo simbólico en algunas zonas del Magreb, hasta ingentes sumas en los países del Golfo, Siria, Jordania, Palestina... donde puede superar en ocasiones los 15000 euros, según pude comprobar en algunos certificados de matrimonio que vi en calidad de traductor jurado. Segundo, el jueves completo, o media jornada, y el viernes, son festivos en la mayoría de los países árabes. A este propósito, existen muchos chistes y caricaturas sobre la elevación de

4. <http://www.nadyelfikr.com/showthread.php?tid=33171>, consultado el 27-04-2014. 
las condiciones de contraer matrimonio en el mundo árabe. Algunos de ellos comparan los procedimientos de casarse con los de otras culturas, como en la siguiente caricatura:

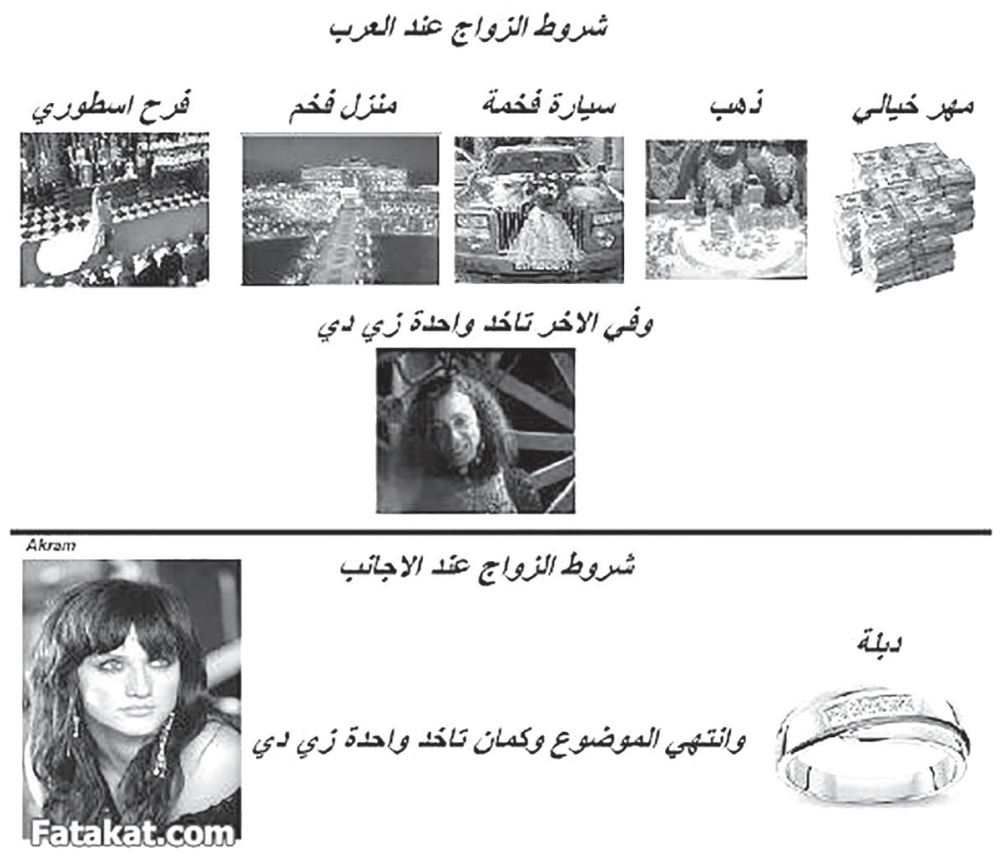

Imagen 4

Las condiciones de matrimonio de los árabes:

Una dote que roza lo imposible (entregada por el novio a la novia), oro, un vehículo y un piso de lujo, y una fiesta a lo grande... Y finalmente te casas con una como esta (la primera mujer).

Las condiciones de matrimonio de los extranjeros (se sobrentiende, occidentales):

Una alianza, y te quitas de más rollos. Finalmente te llevas una como esta (segunda mujer).

Con respecto a la caricatura sobre mujer-esposa-dote de fines de semana, lo que el crítico árabe percibe como "corruptor» en su artículo es el ataque a la estabilidad y a la convivencia de pareja, así como al cuestionamiento de la unión estable y duradera que establecen los códigos culturales árabes. Aunque la conceptualización materialista y cosificadora de la mujer es más sutil en el humor árabe que en el español, esta caricatura no deja de representar a 
la mujer como una cosa que se puede alquilar para un fin de semana. En este caso, como en otros anteriores, en realidad la mujer es una víctima colateral, siendo el objetivo principal el concepto de dote y las trabas familiares al matrimonio. La traducibilidad cultural en este caso, salvando el escollo de la dote, es plena, tanto en un sentido como en otro.

Cabe recordar, como se ha señalado anteriormente, que los chistes árabes tradicionales son menos explícitos que sus homólogos españoles, lo que hace complicado el camino inverso, es decir, traducir chistes españoles al árabe. Además, a la mujer no solo se la objetiviza (muchas veces ni siente, ni piensa), sino que, en ocasiones, se la animaliza, como en este ejemplo español, difícilmente traducible al árabe no por su contenido asociativo, sino porque el collar como gargantilla tiene un nombre y el collar para llevar animales tiene otro:

Dos amigos que se encuentran por la calle:

-Ayer a mi mujer le regalé un collar y está contentísima.

- ¡Ah! Pues yo a la mía la llevo suelta.

En el caso de la cultura árabe clásica los chistes y el humor en general tienen un fuerte calado didáctico y educador. Un adolescente entrevistado por los autores del artículo crítico con las nuevas manifestaciones de los chistes «sucios», citado anteriormente, afirma:

Estos chistes fueron la fuente de mis primeros conocimientos sexuales, primero los oía sin entender a qué se referían, pero ahora los considero un instrumento de diversión y conocimiento 5 .

Así observamos que, cuando decimos que un determinado chiste corporeiza o cosifica a la mujer considerándola un mero instrumento sexual, no hablamos de la «manera» en que se hace en árabe y en español, sino sencillamente del hecho en sí. A diferencia de lo que se podría pensar a priori, la cosificación en árabe es más sutil, más simbólica. El adolescente citado anteriormente, antes de tener conciencia sexual, no los entendía, cosa que difícilmente diría su homólogo español, porque sus chistes son demasiado explícitos y su léxico es denotativo. El aparato sexual y el acto sexual se explicitan sin tapujos en español. De hecho, es esta manera de construcción discursiva y representativa de la mujer la que complica su traducibilidad al árabe, a pesar de la irrupción de una nueva visión ajena a los patrones culturales. De hecho, en la cultura árabe no occidentalizada, el contenido sexual y corporeizador de la mujer es menos explícito que en español. La cosificación de la mujer de forma excesivamente

5. Ibídem.

Feminismo/s 24, diciembre 2014, pp. 245-264 
manifiesta es, podría afirmarse, una novedad en la cultura chistosa árabe, como se ha observado en el artículo citado anteriormente, en el cual se reproducen las palabras de un sociólogo palestino:

Abu Zanat afirma que los chistes verdes ${ }^{6}$ y su excesivo uso y reproducción en distintos contextos de nuestra vida repercuten negativamente en nuestros adolescentes, de tal forma que se pierde la veneración a la vida conyugal y al sexo. Se trivializa, por ello, la vida sexual, a pesar de su consideración como algo fundamental en la vida y el constituyente de la relación de pareja [...]. La mujer encarna en estos chistes el papel del protagonista pasivo, lo que consagra una serie de imágenes estereotipadas sobre la mujer [...]. El uso de la mujer y su representación en el chiste verde no es, sin lugar a dudas, un factor que ayude en la vida. Del mismo modo que la publicidad la presenta como si fuera una mercancía más para promocionar otra, observamos que los chistes representan a la mujer como algo negativo y «bajo» para hacer reír ${ }^{7}$.

Cabe señalar que los chistes verdes en árabe aparecen clasificados en Internet bajo el nombre de «chistes sucios», wisja o wasija. Además, el árabe tradicional considera a la mujer, en lo negativo, un contrincante o rival que pone en duda su hombría y virilidad, pero no una «cosa» inerte y objeto pasivo de acciones -a excepción de algunos chistes construidos sobre los patrones de otros valores culturales-, como en los que se critica en las citas anteriores. Como prueba de esta rivalidad entre hombre y mujer y puesta en duda de las capacidades viriles del árabe, sirva de ejemplo el chiste anteriormente mencionado sobre la perfección en la cocina y en el dormitorio.

Para concluir, diremos que la traducibilidad cultural e intercambiabilidad del chiste sobre la mujer es posible entre culturas por una serie de representaciones que parecen universales:

1. La autoría de los chistes parece masculina. Es como si todos los chistes los inventaran los hombres para reírse entre ellos de la mujer.

2. Una mujer es su cuerpo. Este cuerpo es objeto de uso o de rechazo según las circunstancias. Es más, el chiste español disecciona a la mujer nombrando sin tapujos todas las partes que el hombre desea de ella. En este sentido, la mujer está muy estrechamente relacionada con el uso que se pueda hacer de ella. Parece ser que en el chiste se sustituye el amor por la posesión utilitaria del cuerpo femenino.

3. La mujer no dispone de suficientes capacidades mentales y cognitivas, aunque el chiste árabe es ambivalente en este sentido. La mujer en

6. La expresión «chistes verdes» es la traducción al español de la expresión árabe «chistes sucios».

7. Ibídem.

Feminismo/s 24, diciembre 2014, pp. 245-264 
la cultura árabe popular, incluso en ciertas obras clásicas con buena recepción como Las mil y una noches, es menos tonta que su homóloga española y occidental en general. La árabe «asusta» más al hombre que la española. No obstante, aun así, existen chistes árabes que representan a la mujer como menos capacitada mentalmente, de ahí la paradoja árabe entre mujer «tonta» y mujer «astuta».

4. Como esposa, la mujer tiene prácticamente la misma representación en el chiste árabe y en el español. En ambas culturas chistosas se presenta el matrimonio como favorable para la mujer y desfavorable para el hombre. La mujer en el matrimonio es difícil, es exigente, es mandona, se preocupa por su propio interés más que por el del esposo... En todos los casos, la mujer es una carga en el matrimonio. Son muy reiterados, tanto en el chiste español como en el árabe, los juegos de palabras y de conceptos como el siguiente: «Es fácil morir por una mujer, lo difícil es vivir con ella». El hombre del chiste, tanto árabe como español, descubre que ha sido engañado por el matrimonio una vez que este ha sido consumado. En todos los casos, existe cierto arrepentimiento varonil con respecto a esta institución social. Muy relacionada con la imagen de la mujer casada está la de la suegra, aún más negativa si cabe. Esta representación parece común, por lo que la traducibilidad intercultural en estos casos es posible.

5. Desde el punto de vista de la moral y de los valores, la mujer del chiste parece más relajada éticamente que el hombre, aunque existen notables diferencias con respecto a la cultura árabe, como se ha señalado en el cuerpo de esta investigación. En español, es la mujer la que es infiel, generalmente. La infidelidad del hombre parece casi naturalizada en el chiste. Dicho de otro modo, la infidelidad conyugal femenina es mala, pero la del hombre español parece que no tanto. En este aspecto concreto, la traducibilidad cultural encalla, porque la cultura chistosa árabe no pone demasiado de relieve este tema. Además, es el hombre el que sale mal parado en cuanto a fidelidad conyugal. Es más, se ha observado cierta contradicción en este aspecto entre la representación de la infidelidad femenina en obras árabes clásicas como Las mil y una noches y en los chistes. Es menos frecuente el discurso de la infidelidad en la literatura popular que en el chiste.

Todos estos rasgos que toman en consideración los tres parámetros (físico, intelectual y moral) enunciados en la introducción parecen universales, lo que hace posible la traducción entre culturas. Sin embargo, existen otras particularidades que complican la tarea de la traducibilidad. 
De entre estas particularidades, el chiste español con temática femenina transciende lo lúdico, en ocasiones, para desembocar en el sarcasmo o, incluso, en el insulto, como el chiste sobre la mujer montada en un burro que se presenta como el mismo animal, pero de dos pisos. Estos chistes perderían gracia en árabe. Quizá hagan reír, pero no por lo que dicen, sino por su naturaleza. Es como si el oyente árabe dijera «vaya cómo construyen los españoles sus chistes». No tendrían buena aceptación, ya no por supuestos valores éticos y morales, sino por el mismo procedimiento constructivo de este tipo de chistes. No tiene nada de simbólico, no reta al oyente, no juega con palabras o conceptos ni implica ningún contraste llamativo. Este tipo de chiste no entraría en la categoría de chiste en árabe, sino que se tomaría como un insulto. De hecho, tiene la apariencia de insulto árabe. En árabe, igual que en muchas otras lenguas, el contrincante parece burro, hace, actúa u obra como los burros o cualquier animal que culturalmente se utiliza metafóricamente para degradar a las personas: burros, perros, cerdos, vacas, cabras (Leach, 1974). Así que el animal de dos pisos (que es la mujer) del chiste español, entraría en árabe en la categoría del insulto. Aunque existen chistes árabes sobre personas de zonas determinas (como Lepe, en España), parece ser que la cultura árabe prefiere más bien «reírse» de las situaciones que de las personas.

Es igualmente particular del chiste español el nombramiento directo e insistente de los genitales femeninos o masculinos según el caso, algo que no tendría mucha salida en la cultura árabe. Todos estos órganos tienen nombres metafóricos en árabe. Los chistes sexuales que implican actos entre padres e hijos, existentes en español y muy abundantes en la Red, por lo que se ha evitado reproducirlos en este trabajo, son intraducibles al árabe. Resultan demasiado ofensivos y demasiado inhumanos para un oído árabe. No se han podido encontrar chistes en árabe referentes a esa temática.

Cuando un chiste es sexual, la cultura árabe utiliza eufemismos polisémicos, por lo que el chiste se puede contar incluso en presencia de niños sin que estos entiendan su verdadero sentido. La traducibilidad cultural es por ello unidireccional, se podrían traducir estos chistes del árabe al español, aunque podrían resultar light, pero no se podría hacer el camino inverso. Muchos chistes españoles en los cuales la mujer es objeto sexual explícito son intraducibles e irreproducibles en árabe. Cabe recordar que el hablar de sexo en árabe viene determinado por dos coordenadas fundamentales, tiempo y espacio. Cuando hay diferencias generacionales no se habla de ello. Tampoco se habla de ello en espacios donde confluyen una «mezcla» de edades, sexos, de conocidos y desconocidos. Sin embargo, el simbolismo del chiste árabe con 
temática femenina o sexual y su abstracción permiten sortear dichas limitaciones, aunque siempre entre personas del mismo sexo. Como consecuencia de ello, existe cierta facilidad cultural para traducir del árabe al español, pero no tanto del español al árabe.

\section{Referencias bibliográficas}

Armstrong, Nigel. Translation, Linguistic, Culture: A French-English Handbook. Clevedon, Buffalo, Toronto, Multilingual Matters Ltd, 2005.

BERGSON, Henry. Ensayo sobre el significado de la comicidad. Traducido por: Rafael Blanco. Buenos Aires, Ediciones Godot, 1924 (edición de 2011). Disponible en: <http://www.edicionesgodot.com.ar/sites/default/files/ediciones-godot-larisa.pdf.>, consultado el 11-06-2014.

DE LOS REYes, Pablo. Monólogos. Disponible en <http://www.pablodelosreyes. com/blog/i/1669/65/chiste-de-mis-tetas>, consultado el 06-06-2014.

DRAGHMA, B. y ABU MUALLA, S.: «Los chistes obscenos en ropaje lúdico presentan una falsa cultura sexual». Nadi al fikr al arabi [Club del pensamiento árabe]. Disponible en <http://www.nadyelfikr.com/showthread.php?tid=33171>, consultado el 27-12-2014.

LEACH, Edmund. «Aspectos antropológicos del lenguaje: categorías humanas e injuria verbal». Revista de Occidente. Madrid, Fundación Ortega y Gasset, 1974.

Mateo Martínez-Bartolomé, Marta. La traducción del humor. Oviedo, Universidad de Oviedo, 1995.

Tolosa IGUALADA, Miguel. «De la traducibilidad del chiste: más allá de los factores perceptibles». Interlingüística 16 (2) (2005), pp. 1079-1089.

Vivero García, María Dolores (dirección). Frontières de l'humour. París, L’Harmattan, 2013.

Vivero García, María Dolores (dirección). Humour et crises sociales: Regards croisés France-Espagne. París, L’Harmattan, 2011.

ZabAlbeaesCOA, Patrick. «La traducción del humor en textos audiovisuales», en Miguel Duro (coord.): La traducción para el doblaje y la subtitulación, Madrid, Cátedra, signo e imagen número 63 (2001), pp. 251-263. 